\title{
A Review on Oleaginous Microorganisms for Biological Wastewater Treatment: Current and Future Prospect
}

\author{
Mohammed B. Al Rayaan ${ }^{1 *}$ and, Ibrahim A. Alshayqi ${ }^{2}$ \\ ${ }^{1}$ Department of Environmental Sciences and Engineering, King Abdullah University of Science \& Technology, Thuwal, Saudi Arabia, email: \\ ${ }^{2}$ Department of Environmental Engineering, University of Dammam, Dammam, Saudi Arabia
}

Received: 09/09/2020

Accepted: 16/11/2020

Published: 20/03/2021

\begin{abstract}
The water scarcity issue is becoming a critical issue to the climate change, industrialization and urbanization. Prompt to the advances in biotechnology, Oleaginous microorganisms have been discovered and successfully applied in biological wastewater treatments, which are highly effective for wastewater clean-up and energy efficient lipid conversion to value-added products. This paper aims to review the recent advances of the application of different types of Oleaginous microorganisms (e.g. yeasts, microalgae, and fungi) as well as the advantages, limitations and application fields (food industry, municipal waste and chemical plant). The future prospect and challenges of Oleaginous microorganism that warrant in environmental settings or engineered systems are also highlighted in the review. In order to improve the Technology Readiness Level (TRL), the future research direction should be more focussed on the economic and environmental studies.
\end{abstract}

Keywords: Oleaginous microorganisms; Biological wastewater treatment; Microalgae; Industrial application

\section{Introduction}

The fresh water demand is rapidly increasing due to urbanization and industrialization, and predicted to beyond than $55 \%$ in by the year of 2025 [1]. In recent year, "wastewater treatment field" is becoming a hot topic in both academic and industrial community to eliminate both chemical and microbial pollutants from municipal/industrial wastewater [2]. Nevertheless, the reuse of water from treated wastewater effluents can pose a serios health issue due to contamination such as microbial pollutants, heavy metals, suspended solid and organic matters [3]. To date, biological treatment is well-acknowledged as one of the most eco-friendly and cost-effective way to remove those contaminants from wastewater [1, 4-8]. Notably, the use of Oleaginous microorganisms in biological treatment of wastewater is much attractive as compared with the traditional aerobic digestion and anaerobic digestion technologies which requires high-end system such as up-flow anaerobic sludge blanket digestion or expanded granular sludge bed digestion [9-11]

Apart from cost-effectiveness, Oleaginous microorganisms can clean up the wastewaters effectively within a short period with valuable generation of some value-added products as shown in Fig. 1. For instance, Chlorella pseudolambica has been studied in livestock wastewater for biodiesel production [12]; Sterigmatomyces halophilus has been applied in textile dyeing wastewater for bioremediation [13]; and Chlorella vulgaris has been reported for biochar production using rich in ammonia-N swine wastewater as source of nutrient [14]. Most importantly, the valorisation of Oleaginous microorganisms in low-cost substrates like nutrient-rich wastewaters is a circular economy concept that can help improve the economic feasibility of the wastewater treatment plants related industries with a net positive value. Thus, in this review, we aim to provide a comprehensive insight on the advances of wastewaters treatment by Oleaginous microorganisms which includes 1) The types of Oleaginous microorganisms used for biological treatment such as microalgae, yeast, fungi and bacteria; 2) The industrial application of Oleaginous microorganisms such as food, pharmaceutical and municipal waste industries and also; 3) The commercialization attractiveness and challenges of the technology.

\section{Types of Oleaginous microorganisms used for biological treatment of wastewaters}

Most of the studies have reported that Oleaginous microorganisms accumulate a high lipid content in the range of $14-75 \%$ of their dry weight [15-20]. To date, Botryococcus braunii is reported as one of the richest lipid content microorganisms in which $74.5 \%$ of lipid (58.8\% nonpolar lipids and $15.7 \%$ polar lipids) can be extracted [21].

Corresponding author: Mohammed B. Al Rayaan, Department of Environmental Sciences and Engineering, King Abdullah University of Science \& Technology, Thuwal, Saudi Arabia, Email: Mohammed.alrayaan@kaust.edu.sa 

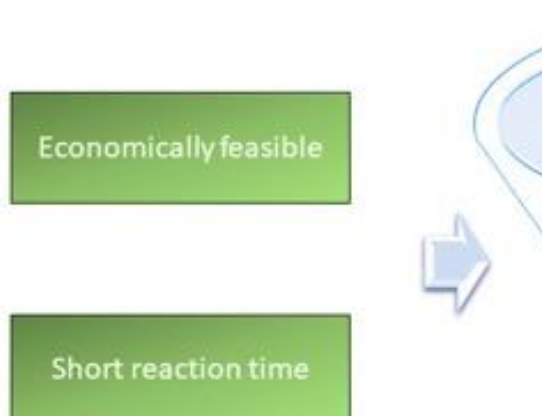

Wastewater

(Food industry, Municipal waste, Chemical Plant

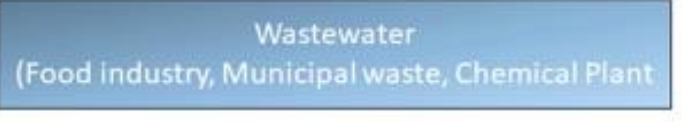

1
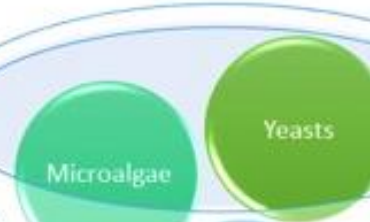

1
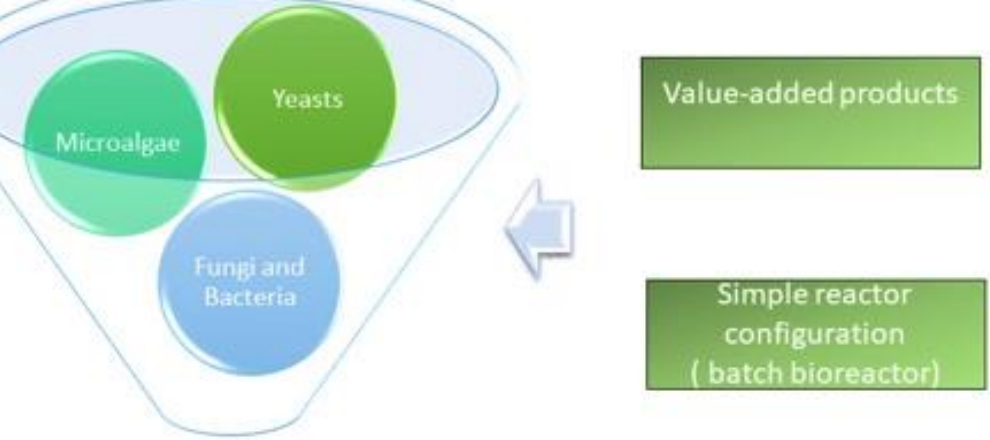

\section{Regenerated}

Fresh water

Figure 1: Application of Oleaginous microorganisms for biological treatment of wastewaters

Table 1: Application of Oleaginous microorganisms in biological wastewater treatment for bio-energy production

\begin{tabular}{|c|c|c|c|c|}
\hline Microorganism & Feedstock & Culture mode & Products & Ref \\
\hline Candida lipolytica & Molasses & Batch & Biodiesel & [22] \\
\hline Cryptococcus laurentii & Winery & Batch & Biodiesel/Bio-oil & [23] \\
\hline Trichosporon fermentans & Molasses & Batch & Biodiesel & [24] \\
\hline Trichosporon dermatis & Butanol (ABE) fermentation & Batch & Biodiesel & [25] \\
\hline Chlorella vulgaris & Artificial wastewater & Batch & Biodiesel & [26] \\
\hline Scenedesmus sp. & Starch-containing textile wastewater & Batch & Biogas & [27] \\
\hline Scenedesmus sp. & $\mathrm{ABE}$ fermentation & Fed-batch & Biogas & [28] \\
\hline Rhodococcus opacus & Refinery wastewater & Batch & Bio-oil & [29] \\
\hline Chlorella vulgaris & Municipal waste & Batch & Bio-oil & [30] \\
\hline
\end{tabular}

Table 2: Application of Oleaginous yeast for wastewaters treatment

\begin{tabular}{|c|c|c|c|c|c|}
\hline Yeast & Substrate & Biomass (g L-1) & Lipid content (\%) & COD removal (\%) & Ref \\
\hline Rhodotorula glutinis & Brewery effluents & 5.2 & 15.0 & - & [36] \\
\hline Rhodotorula glutinis & Corn starch farm & 40.0 & 35.0 & 80.0 & [37] \\
\hline Arthrospira platensis & Dairy farm & 4.9 & 30.2 & 98.0 & [38] \\
\hline Rhodococcus opacus & Dairy farm & 0.7 & 53.2 & 100.0 & [39] \\
\hline Oleaginous consortium & Municipal wastewater & 0.6 & 20.0 & 81.0 & [40] \\
\hline Lipomyces starkeyi & Potato starch wastewater & 2.6 & 8.9 & - & [41] \\
\hline Botryococcus braunii & N-rich wastewater & 2.3 & 30.3 & - & [42] \\
\hline
\end{tabular}

Table 1 shows a series of Oleaginious microorganisms that have been utilized for wastewater biological treatment to produce various products such as biodiesel, biogas and bio-oil.

\subsection{Oleaginous yeasts}

Oleaginous yeasts are capable of accumulating over $20 \%$ of their cell mass as intracellular lipids, high growth rate as well as large capacity for substrate consumption [31]. Typical Oleaginous yeasts strains that being investigated are e.g. Yarrowia lipolytica, Rhodotorula glutinis, Rhodosporidium toruloides, Cryptococcus curvatus, Trichosporon pullulan and Lipomyces lipofer as shown in Table 2 [32-34]. For example, 
Trichosporon cutaneum ACCC 20271 is investigated in an ethanol fermentation wastewater medium by Wang et al. [35]. Without any pre-treatment or external nutrient, it is able to accumulate significant lipid quantities $(2.16 \mathrm{~g} \mathrm{~L}-1)$ and remove ca. $55 \%$ of COD after a 5-day culture. Meanwhile, Peng's group has reported that Trichosporon dermatis has a high biomass and lipid content of $7.4 \mathrm{~g} \mathrm{~L}-1$ and $13.5 \%$, respectively [25]. Notably, $68 \%$ of COD from butanol fermentation wastewater-based medium is removed after 5 days of fermentation, indicating that Trichosporon dermatis is a potential candidate for large scale wastewater treatment.

\subsection{Oleaginous Microalgae}

Microalgae are one of the potential candidates for the biological treatment in wastewater facilities, as autotrophic cultivation of microalgae in wastewater open ponds that can enhance the growth as well as the amount of lipid content through consumption of the nutrient the wastewater stream [43-46]. Also, the ambient $\mathrm{CO} 2$ can be sequestered for microalgae growth which helps to reduce the global carbon's footprint [47]. Thus, the use of wastewater during the heterotrophic growth conditions for microalgae is an economic feasible process for biodiesel production. The types of Oleaginous microalgae genus reported for simultaneous lipid production and biological wastewater treatment are shown Table 3. In 2011, Feng et al. have replicated an artificial wastewater to cultivate Chlorella vulgaris in a column aeration photobioreactor under batch and semi-continuous configuration. The highest lipids content (42\%) with $86 \%$ of COD removal and $97 \%$ of $\mathrm{NH} 4+$ are attained in the semi-continuous cultivation with daily replacement of 1.01 of the 2.01 culture [26]. Meanwhile, Hena et al. have also reported similar good result in which that the dairy farm wastewater is a suitable medium for cultivation of Arthrospira Platensis, producing a high biomass yield of $4.98 \mathrm{~g} \mathrm{~L}-1$ that contains $30.23 \%$ of lipids and $98 \% \mathrm{COD}$ and nutrients. Although the growth period of microalgae is relatively longer when compared with other microorganisms, microalgae is still a better alternative as it can survive in harsh low nutrient concentration wastewaters environment due to its autotrophic character [48].

\subsection{Oleaginous Fungi and Bacteria}

The application of fungi and bacteria in wastewater purification is much lesser as compared to its counterparts' microalgae and yeasts. Up to date, only a few literature has been reported using Oleaginous fungi namely Aspergillus oryzae [53]ᄀ, Trichoderma reesei $\neg[54]$, Rhodococcus opacus [39], Rhodococcus sp. [55] as shown in Table 4. Minaraj and coauthors have investigated the ability of Rhodococcus opacus in removing the COD of dairy wastewater [53]. They claimed that the bacteria managed to yield up to $14.28 \%$ of lipid content and COD removal of $30 \%$ without addition of any substrate. Meanwhile, with the addition of mineral salts as external substrate, the lipid content and the COD removal efficiency have increases up to $33 \%$ and $62 \%$, respectively. Similar observation has been obtained by Gupta et al where the application of Rhodococcus opacus could remove up to almost $100 \%$ of COD with a maximum lipid yield of $1.8 \mathrm{~g} \mathrm{~L}^{-1}$ at a retention time of 6.6 hr [39].

\section{Application of Wastewater Treatment by Oleaginous Microorganisms 3.1 Food industry}

The strategy of using Oleaginous microorganism for treating wastewater from food waste industry are gaining popularity in solving wastewater pollution and reducing the greenhouse emission [53, 56, 57]. Recently, many researchers have demonstrated that Oleaginous microorganism can be used to treat wastewaters discharged from a wide spectrum of food industries including Monosodium glutamate [58], olive oil [59], soybean [60], and starch [61]. The rationale behind such application is due to wastewater from food industry has high BOD and COD contents, which contributes to its intrinsically high fermentability. Thus, it can be treated easily from conventional anaerobic digestion method. Anbarasan et al. have inoculated Metschnikowia Pulcherrima using the distillery wastewater and produced biodiesel from the lipids accumulated by the microorganism [62].

Table 3: Application of Oleaginous microalgae for wastewaters treatment

\begin{tabular}{|c|c|c|c|c|c|}
\hline Microalgae & Substrate & Biomass (g L-1) & Lipid content (\%) & COD removal $(\%)$ & Ref \\
\hline Chlorella protothecoides & Thiocyanate wastewater & 1.3 & 30.6 & - & [49] \\
\hline Arthrospira platensis & Olive-oil mill wastewater & 1.7 & 16.9 & 73.1 & [50] \\
\hline Aspergillus sp. & Corncob waste liquor & 2.0 & 22.1 & 60.0 & [51] \\
\hline Botryococcus braunii & $\mathrm{N}$-rich wastewater & 2.2 & 30.2 & - & [42] \\
\hline Scenedesmus obliquus & Secondary effluent & - & 17.0 & 1.3 & {$[52]$} \\
\hline Scenedesmus sp. & Secondary effluent & - & 12.7 & 1.0 & [52] \\
\hline Scenedesmus quadricauda & Secondary effluent & - & 66.1 & 1.7 & [52] \\
\hline
\end{tabular}

Table 4: Application of Oleaginous fungi and bacteria for wastewaters treatment

\begin{tabular}{|c|c|c|c|c|c|}
\hline Fungi and Bacteria & Substrate & Biomass (g L-1) & Lipid content (\%) & COD removal $(\%)$ & Ref \\
\hline Aspergillus oryzae & Potato processing wastewater & - & $3.5 \mathrm{~g} / \mathrm{L}$ & 91.0 & [53] \\
\hline Mucor circinelloides & Equalization tank wastewater & 0.6 & 22.1 & 88.7 & [54] \\
\hline Trichoderma reesei & Equalization tank wastewater & 0.7 & 9.8 & 86.7 & [54] \\
\hline Rhodococcus opacus & Dairy wastewater & - & 53.2 & 100 & [39] \\
\hline Rhodococcus opacus & Primary effluent & - & - & 81.0 & [40] \\
\hline Rhodococcus sp. RHA1 & Thermomechanical pulping effluent & - & - & 48.0 & [55] \\
\hline
\end{tabular}


The in-situ transesterification reaction is performed using sodium hydroxide and methanol under base catalysis and the biodiesel yield was reported as high as $1.4 \mathrm{~g} / \mathrm{L}$. Furthermore, Xue et al. have demonstrated an excellent COD removal of $80 \%$ by treating potato processing wastewater using Rhodotorula glutinis[63]. The COD removal performance in former study is comparably higher than that reported in previous studies of Honyang et.al [64] and Muniraj et.al [65]. In a recent study, a mixculture of yeast (Rhodosporidum. Toruloides) and microalgae (Chlorella vulgaris) is introduced in a culturing and treating the food waste hydrolysate (see Fig. 2(a)) [66]. Based on the findings, the mix-culture of yeast and culture promoted a higher removal performance of organic matters from wastewater and better lipid production at a shorter cultivation time as compared to the pure culture of yeast and microalgae. Under the mutualistic relationship of both yeast and microalgae, yeasts provide $\mathrm{CO} 2$ for microalgae meanwhile microalgae offer oxygen for the yeasts. Furthermore, yeasts mainly consume organic matters and microalgae uptake nitrogen and phosphorus from the wastewater. Thus, mix-culture of yeast and microalgae using food waste hydrolysate as a culture medium is a dual propose strategy in solving the waste disposal issues and alarming energy crisis. As evidence in Fig. 2(b), it showed that the final biomass and substrate utilization ratio of mixed culture is highest at $20 \%$ inoculum size of Chlorella vulgaris, the lipid production, lipid content, biomass yield and lipid yield are highest at $10 \%$ when the
Rhodosporidum. Toruloides Inoculum size fixed at 5\%. However, the application of yeast is generally less effective in nutrient removal due to its poor resistance to high organic matter nonsterile wastewater. Up to now, only a few studies have been performed to produce microbial lipid from high strength nonsterile wastewater in the absence of other nutrients for the mixed culture of yeast and microalgae. Future research works should be conducted on producing microbial lipid from non-sterile wastewater as the results could give an insight on bridging the gap between research and industrial practice.

\subsection{Municipal wastewater}

Lately, there has been a great upsurge of interest in studies related to several aspect of municipal wastewater treatment. Amongst the treatment methods reported in literature, anaerobicaerobic digestion treatment is one of the methods widely reported and used in treating the municipal wastewater [67-69]. In recent years, Oleaginous microorganism has been proven as one of the promising biological sources in treating municipal wastewater. For example, Goswami et al. explored on the valorisation of biomass gasification wastewater for lipid accumulation by using Rhodococcus apacus and the potential application of biodiesel production [70]. Using the raw biomass gasification water as the synthetic mineral media, the high cell density lipid rich bacterium exhibited an excellent lipid yield of $54.3 \%$ with high wastewater COD removal efficiency of $64 \%$. a)

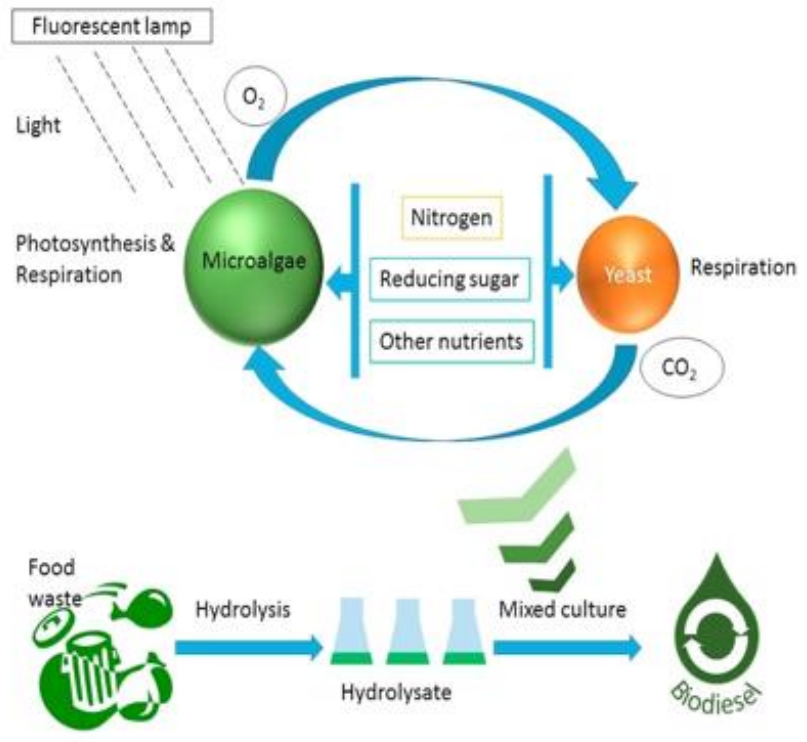

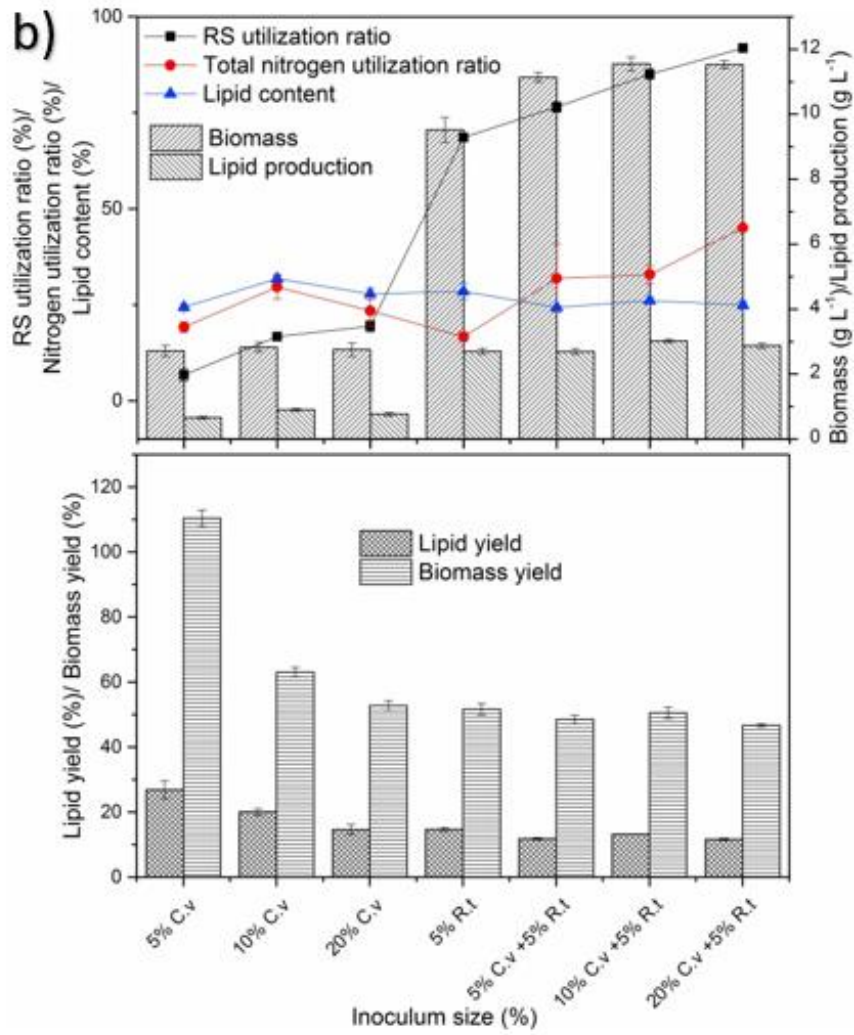

Figure 2: (a) Application of co-culture of microalgae and yeast in treating wastewater derived from food industry, (b) Nitrogen utilization ratio and lipid content extraction from Pure and mixed culture of R. toruloides and C. vulgaris at different inoculum size ratio in FWH. (adapted from [62]) 
From the transesterification of bacterial lipids to biodiesel, it is revealed that the Rhodococcus apacus bacterial strain has a good potential in treating the biomass gasification wastewater and producing biodiesel. In the same vein, Eida et al. have isolated a local Scenedesmus obliquus from wastewater swamp and cultivated it using secondary treated domestic wastewater for biomass and lipid production [71]. From the results, the secondary treated municipal wastewater is proven to be an economical growth medium for the microalgae cultivation and lipid production. Similar to treatment of food industry wastewater, coculture of Oleaginous yeast and algae is also reported to be one of the effective strategies in treating municipal wastewater and producing lipids.

In another study of Cho et.al [72], instead of using a single strain of microalgae, a consortium of indigenous microalgae and bacterial from raw municipal wastewater is used for biomass and lipid production. Three different cultivation phases of microalgae and bacteria in raw municipal wastewater in lab-scale photobioreactors operated in circulating batch mode are investigated. From Fig.3, the initial phase I cultivation is performed using only raw municipal wastewater, where phase II and III are replaced with effluent from the sewage sludge fermentation. As a result, a stepwise increment of biologically produced volatile fatty acids in phase II and III can be observed at the beginning of phase II and III. The highest algal biomass production of $117.1+2.7 \mathrm{mg} / \mathrm{L} / \mathrm{d}$ and highest lipid productivity of $17.2+0.2 \mathrm{mg} / \mathrm{L} / \mathrm{d}$ are attained at phase II and III, respectively. As a whole, the stepwise additional of biologically produced volatile fatty acids promoted the microalgae biomass and lipid productions with better nutrient removal performance. However, future studies must be performed to isolate the consortium of indigenous microalgae and bacterial from raw municipal wastewater and expound the individual effect of each microalgae or bacterial strain to biomass and lipid productivity in a photobioreactor. Likewise, consortium of Oleaginous yeasts and bacterium also exhibited excellent COD removal performance (above $81 \%$ ) when it is used to treat municipal wastewater [73, 74].

\subsection{Chemical plant}

Wastewater pollution from chemical plants is widely recognized as one of the serious threats to human population and ecosystem due to the discharge of toxic effluents to the surrounding environments. To combat this challenge, the application of Oleaginous bacterial, yeast and microalgae in an integrated application of toxic chemical removal and sustainable biodiesel production have been studied and reported in many previous studies. For instance, pulp and paper industry is one of the main environmental polluters after oil, leather, cement, steel and textile industries. According to the literature, approximately 100 million $\mathrm{kg}$ of hazardous contaminants including sodium hydroxide, chlorinated phenol, lignin and other derivatives with high COD are discharged into the environment every year from the paper industry [75]. This raised serious environmental concerns and consequences to our wildlands and communities.

Fig. 4 illustrates the process flow of pulp and paper industry wastewater for Oleaginious yeast cultivation and biodiesel production. It is reported that Rhodosporidium kratochvilovae has unique ability to utilize the pulp and paper industry effluent as a culture medium and accumulate high quantity of triacylglycerol or neutral lipids $(8.56 \mathrm{~g} / \mathrm{L})$.

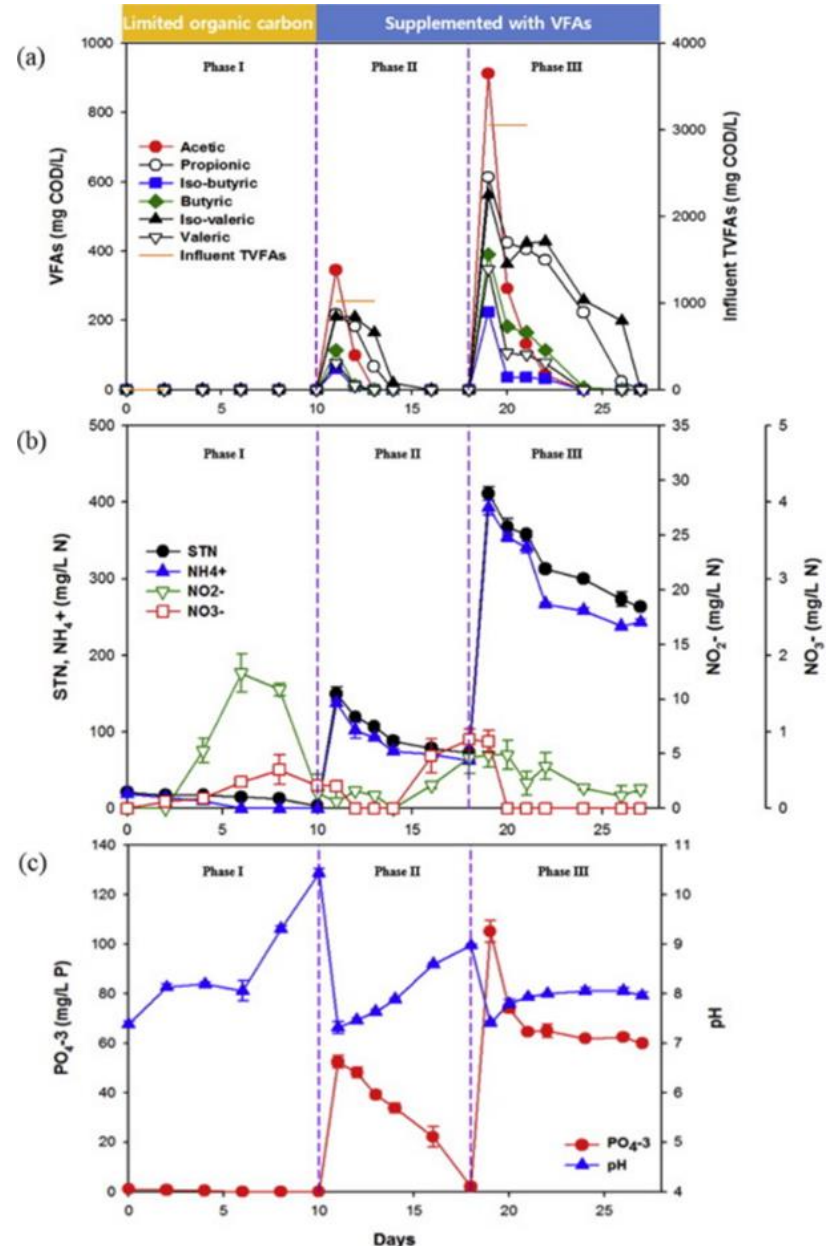

Figure 3: Changes of chemical components in consortium of microalgae and bacterial with stepwise increment of biologically produced volatile fatty acids circulating within the photobioreactor: (a) VFAs, (b) STN $\mathrm{NH} 4+, \mathrm{NO}_{2}-$, and $\mathrm{NO}_{-}-$, (c) $\mathrm{pH}$ and PO4-3. Ad Adopted from [68]

It also possessed superior phenol (99.60\%) and lignin (94.2\%) removal performances with high COD $(94.22 \%)$ and BOD $(84.59 \%)$ removal efficiencies [75]. Interestingly, the biodiesel obtained from the extracted triacylglycerol has desired biofuel properties including high cetane number, better oxidation stability, and improved cold flow properties. Taking Deeba et al. study as an example, the Cryptococcus vishniaccii (MTCC 232) strain has been used to convert paper mill sludge into neutral lipids for sustainable biodiesel production. From the results, the paper mill sludge extracts have all the essential nutrients for the culture of Oleaginious yeast and the bacterial strain exhibited enhanced triaclyglycerides production of $5.5+0.8 \mathrm{~g} / \mathrm{L}$ [76]. Also, the biodiesel obtained from the transesterification of the accumulated triglycerides is enriched in oleic acid, palmitic acid, linoleic acid, and stearic acid with better oxidative stability and biodiesel quality. 


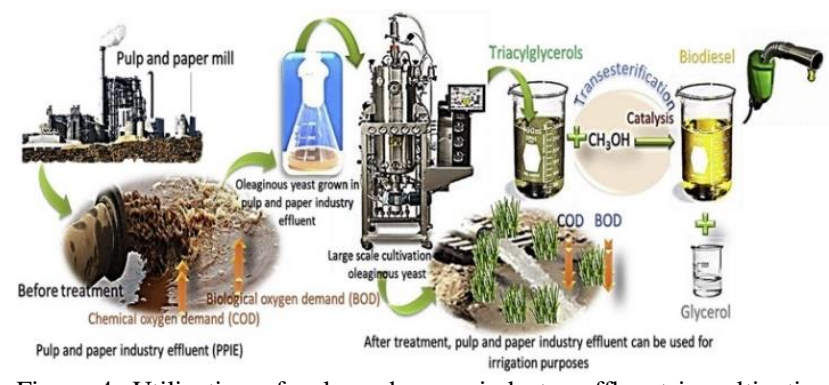

Figure 4: Utilization of pulp and paper industry effluent in cultivating Oleaginous yeast and producing sustainable biodiesel [71]

Other than paper and pulp industry, industrialization processes including textile, leather, dyeing, cosmetic and pharmaceutical industries have an increasing demand for synthetic lignin-like dyes. Discharge of such hazardous effluents from these industries into water bodies will ultimately give rise to detrimental effects to the environments and aquatic flora. Besides that, the use of oleaginous microorganism including yeast, bacterial and fungi offers another environmentally friendly biological remediation method to decolorize recalcitrant synthetic dyes and valorising lignin while producing sustainable biodiesel. Such method also offers low operating cost, low energy requirement, easy process control, and also the excellent operation flexibility under a wide range of conditions.

In a recent study of Ali et.a 1 [77], a novel oleaginous yeast consortium, OYC-YBC.SH is developed using three yeast cultures (Viz. Yarrowia sp. SSA1642, Barnettozyma californica SSA1518 and Sterigmatomyces halophilus SSA1511) for textile dye removal, lignin valorisation and lipid production. The oleaginous yeast consortium exhibited superior decolorization performance when tested with real dyeing effluent sample at $\mathrm{pH}$ 8. It is able to grow on a wide range of carbon sources with the highest lipid productivity of $1.56 \mathrm{~g} / \mathrm{L} /$ day and lipid activity of $170.3 \mathrm{U} / \mathrm{mL}$ Moreover, substantial detoxification performance is also observed when the textile effluent sample is treated with OYC-Y.BC.SH consortium under static conditions at $30{ }^{\circ} \mathrm{C}$ for $24 \mathrm{hrs}$, which further suggesting its suitability for degrading most of the textile constituents under alkaline $\mathrm{pH}$ environments. The TOC, BOD, COD and color removal performances are reported as $54 \%, 74 \%, 95 \%$ and $98 \%$, respectively.

\section{Challenges of the application of oleaginous microorganisms in industrial wastewater treatment}

As discussed in the above, the use of oleaginous microorganisms is a breakthrough in wastewater treatment as they are inexpensive, environmentally friendly, simple system configuration as well as short fermentation period [78-80]. However, the COD removal by oleaginous microorganisms is still far lower than that of traditional chemical technologies. In fact, the total COD removal of industrial and municipal wastewaters can be up to $95 \%$ by using the ion exchange or chemical reduction [81-83]. On top of that, the COD removal obtained by the conventional biological anaerobic-aerobic biological treatment $(80-90 \%)$ is also much higher than the use of oleaginous microorganisms [67].

\section{Conclusions}

The application of Oleaginous microorganisms is a win-win strategy where the nutrient-rich wastewaters can be act as the medium to produce bioenergy and also, the unwanted nutrient or COD can be removed simultaneously. Owing to its advantages, the application of oleaginous microorganisms in industrial scale seems feasible only if the challenges mentioned above can be resolved. The future research direction should be more focussed on the economic and environmental studies in order to benchmark with the conventional biological (anaerobic) and chemical wastewater treatment.

\section{Ethical issue}

Authors are aware of, and comply with, best practice in publication ethics specifically with regard to authorship (avoidance of guest authorship), dual submission, manipulation of figures, competing interests and compliance with policies on research ethics. Authors adhere to publication requirements that submitted work is original and has not been published elsewhere in any language.

\section{Competing interests}

The authors declare that there is no conflict of interest that would prejudice the impartiality of this scientific work.

\section{Authors' contribution}

All authors of this study have a complete contribution for data collection, data analyses and manuscript writing.

\section{References}

1. Meena, R. A. A., Yukesh Kannah, R., Sindhu, J., Ragavi, J., Kumar, G., Gunasekaran, M., \& Rajesh Banu, J. Trends and resource recovery in biological wastewater treatment system. Bioresource Technology Reports. https://doi.org/10.1016/j.biteb.2019.100235

2. Tran, N. H., Ngo, H. H., Urase, T., \& Gin, K. Y. H. A critical review on characterization strategies of organic matter for wastewater and water treatment processes. Bioresource Technology. 2015 https://doi.org/10.1016/j.biortech.2015.06.091

3. Luo, Y., Guo, W., Ngo, H. H., Nghiem, L. D., Hai, F. I., Zhang, J., Liang, S., \& Wang, X. C. A review on the occurrence of micropollutants in the aquatic environment and their fate and removal during wastewater treatment. Science of the Total Environment. 2014. https://doi.org/10.1016/j.scitotenv.2013.12.065

4. Kikuchi, T., \& Tanaka, S. Biological removal and recovery of toxic heavy metals in water environment. Critical Reviews in Environmental Science and Technology. 2012. https://doi.org/10.1080/10643389.2011.651343

5. Maddela, N. R., Sheng, B., Yuan, S., Zhou, Z., Villamar-Torres, R., \& Meng, F. Roles of quorum sensing in biological wastewater treatment: A critical review. Chemosphere. 2019. https://doi.org/10.1016/j.chemosphere.2019.01.064

6. Abu Hasan, H., Muhammad, M. H., \& Ismail, N. I. A review of biological drinking water treatment technologies for contaminants removal from polluted water resources. Journal of Water Process Engineering. 2020. https://doi.org/10.1016/j.jwpe.2019.101035

7. Saleh, I. A., Zouari, N., \& Al-Ghouti, M. A. Removal of pesticides from water and wastewater: Chemical, physical and biological treatment approaches. Environmental Technology and Innovation. 2020. https://doi.org/10.1016/j.eti.2020.101026

8. Sousi, M., Liu, G., Salinas-Rodriguez, S. G., Chen, L., Dusseldorp, J., Wessels, P., Schippers, J. C., Kennedy, M. D., \& van der Meer, W. Multi-parametric assessment of biological stability of drinking water 
produced from groundwater: Reverse osmosis vs. conventional treatment. Water $\quad$ Research. 2020. https://doi.org/10.1016/j.watres.2020.116317

9. Colussi, I., Cortesi, A., Vedova, L. Della, Gallo, V., \& Robles, F. K. C. Start-up procedures and analysis of heavy metals inhibition on methanogenic activity in EGSB reactor. Bioresource Technology. 2009. https://doi.org/10.1016/j.biortech.2009.07.041

10. Lettinga, G., van Velsen, A. F. M., Hobma, S. W., de Zeeuw, W., \& Klapwijk, A. Use of the upflow sludge blanket (USB) reactor concept for biological wastewater treatment, especially for anaerobic treatment. Biotechnology and bioengineering. 1980. https://doi.org/10.1002/bit.260220402

11. Kato MT, Field JA, Versteeg P, Lettinga G. Feasibility of expanded granular sludge bed reactors for the anaerobic treatment of lowstrength soluble wastewaters. Biotechnology and bioengineering. 1994. https://doi.org/10.1002/bit.260440410

12. Chung, J., Lee, I., \& Han, J. I. Biodiesel production from oleaginous yeasts using livestock wastewater as nutrient source after phosphate struvite recovery. $\quad$ Fuel. 2016. https://doi.org/10.1016/j.fuel.2016.08.084

13. Ali, S. S., Al-Tohamy, R., Koutra, E., El-Naggar, A. H., Kornaros, M., \& Sun, J. Valorizing lignin-like dyes and textile dyeing wastewater by a newly constructed lipid-producing and lignin modifying oleaginous yeast consortium valued for biodiesel and bioremediation. Journal of Hazardous Materials. 2021. https://doi.org/10.1016/j.jhazmat.2020.123575

14. Nagarajan, D., Kusmayadi, A., Yen, H. W., Dong, C. Di, Lee, D. J., \& Chang, J. S. Current advances in biological swine wastewater treatment using microalgae-based processes. Bioresource Technology. 2019. https://doi.org/10.1016/j.biortech.2019.121718

15. Chatzifragkou, A., Makri, A., Belka, A., Bellou, S., Mavrou, M., Mastoridou, M., Mystrioti, P., Onjaro, G., Aggelis, G., \& Papanikolaou, S. Biotechnological conversions of biodiesel derived waste glycerol by yeast and fungal species. Energy. 2011. https://doi.org/10.1016/j.energy.2010.11.040

16. Economou, C. N., Aggelis, G., Pavlou, S., \& Vayenas, D. V. Single cell oil production from rice hulls hydrolysate. Bioresource Technology. 2011. https://doi.org/10.1016/j.biortech.2011.08.025

17. Ratledge, C. Single cell oils - have they a biotechnological future?. Trends in Biotechnology. 1993. https://doi.org/https://doi.org/10.1016/0167-7799(93)90015-2

18. Spolaore, P., Joannis-Cassan, C., Duran, E., \& Isambert, A. Commercial applications of microalgae. Journal of Bioscience and Bioengineering. 2006. https://doi.org/10.1263/jbb.101.87

19. Alvarez, H. M., Kalscheuer, R., \& Steinbüchel, A. Accumulation of storage lipids in species of Rhodococcus and Nocardia and effect of inhibitors and polyethylene glycol. Lipid / Fett. 1997. https://doi.org/https://doi.org/10.1002/lipi.19970990704

20. Covarrubias, S. A., De-Bashan, L. E., Moreno, M., \& Bashan, Y. Alginate beads provide a beneficial physical barrier against native microorganisms in wastewater treated with immobilized bacteria and microalgae. Applied Microbiology and Biotechnology. 2012. https://doi.org/10.1007/s00253-011-3585-8

21. Yamaguchi, K., Nakano, H., Murakami, M., Konosu, S., Nakayama, O., Kanda, M., Nakamura, A., \& Iwamoto, H. Lipid composition of a green alga, botryococcus braunii. Agricultural and Biological Chemistry. 1987. https://doi.org/10.1080/00021369.1987.10868040

22. Karatay, S. E., \& Dönmez, G. Improving the lipid accumulation properties of the yeast cells for biodiesel production using molasses. Bioresource Technology.

2010 . https://doi.org/https://doi.org/10.1016/j.biortech.2010.05.054

23. Santos, C., Lucas, M. S., Dias, A. A., Bezerra, R. M. F., Peres, J. A., \& Sampaio, A. Winery wastewater treatment by combination of Cryptococcus laurentii and Fenton's reagent. Chemosphere. 2014. https://doi.org/https://doi.org/10.1016/j.chemosphere.2014.05.083

24. Zhu, L. Y., Zong, M. H., \& Wu, H. Efficient lipid production with Trichosporonfermentans and its use for biodiesel preparation.
Bioresource Technology.

https://doi.org/https://doi.org/10.1016/i.biortech.2008.02.033

2008.

25. Peng, W., Huang, C., Chen, X., Xiong, L., Chen, X., Chen, Y., \& Ma L. Microbial conversion of wastewater from butanol fermentation to microbial oil by oleaginous yeast Trichosporon dermatis. Renewable Energy. https://doi.org/https://doi.org/10.1016/j.renene.2012.12.017

26. Feng, Y., Li, C., \& Zhang, D. Lipid production of Chlorella vulgaris cultured in artificial wastewater medium. Bioresource Technology. 2011. https://doi.org/https://doi.org/10.1016/j.biortech.2010.06.016

27. Lin, C.-Y., Nguyen, M.-L. T., \& Lay, C.-H. Starch-containing textile wastewater treatment for biogas and microalgae biomass production. $\begin{array}{llll}\text { Journal of } & \text { Cleaner }\end{array}$ https://doi.org/https://doi.org/10.1016/j.jclepro.2017.09.036

28. Nagarajan, D., Lee, D.-J., \& Chang, J.-S. Integration of anaerobic digestion and microalgal cultivation for digestate bioremediation and biogas upgrading. Bioresource Technology. 2019. https://doi.org/https://doi.org/10.1016/j.biortech.2019.121804

29. Paul, T., Sinharoy, A., Pakshirajan, K., \& Pugazhenthi, G. Lipid-rich bacterial biomass production using refinery wastewater in a bubble column bioreactor for bio-oil conversion by hydrothermal liquefaction. Journal of Water Process Engineering. 2020 https://doi.org/https://doi.org/10.1016/i.jwpe.2020.101462

30. Goswami, G., Makut, B. B., \& Das, D. Sustainable production of biocrude oil via hydrothermal liquefaction of symbiotically grown biomass of microalgae-bacteria coupled with effective wastewater treatment. Scientific Reports. 2019. https://doi.org/10.1038/s41598019-51315-5

31. Lamers, D., van Biezen, N., Martens, D., Peters, L., van de Zilver, E., Jacobs-van Dreumel, N., Wijffels, R. H., \& Lokman, C. Selection of oleaginous yeasts for fatty acid production. BMC Biotechnology. 2016. https://doi.org/10.1186/s12896-016-0276-7

32. Li, Q., Du, W., \& Liu, D. Perspectives of microbial oils for biodiesel production. Applied Microbiology and Biotechnology. 2008. https://doi.org/10.1007/s00253-008-1625-9

33. Zhang, J., Fang, X., Zhu, X.-L., Li, Y., Xu, H.-P., Zhao, B.-F., Chen, L., \& Zhang, X.-D. Microbial lipid production by the oleaginous yeast Cryptococcus curvatus $\mathrm{O} 3$ grown in fed-batch culture. Biomass \& bioenergy. 2011. https://doi.org/10.1016/j.biombioe.2011.01.024

34. Evans, C. T., \& Ratledge, C. Phosphofructokinase and the Regulation of the Flux of Carbon from Glucose to Lipid in the Oleaginous Yeast Rhodosporidium toruloides . Microbiology (Society for General Microbiology). 1984. https://doi.org/10.1099/00221287-130-12-325

35. Wang, J., Hu, M., Zhang, H., \& Bao, J. Converting Chemical Oxygen Demand (COD) of Cellulosic Ethanol Fermentation Wastewater into Microbial Lipid by Oleaginous Yeast Trichosporon cutaneum. Applied biochemistry and biotechnology. 2017. https://doi.org/10.1007/s12010-016-2386-Z

36. Schneider, T., Graeff-Hönninger, S., French, W. T., Hernandez, R., Merkt, N., Claupein, W., Hetrick, M., \& Pham, P. Lipid and carotenoid production by oleaginous red yeast Rhodotorula glutinis cultivated on brewery effluents. Energy (Oxford). 2013 https://doi.org/10.1016/j.energy.2012.12.026

37. Xue, F., Gao, B., Zhu, Y., Zhang, X., Feng, W., \& Tan, T. Pilot-scale production of microbial lipid using starch wastewater as raw material. Bioresource technology. https://doi.org/10.1016/j.biortech.2010.01.124

38. Hena, S., Znad, H., Heong, K. T., \& Judd, S. Dairy farm wastewater treatment and lipid accumulation by Arthrospira platensis. Water research (Oxford). https://doi.org/10.1016/j.watres.2017.10.057

39. Gupta, N., Manikandan, N. A., \& Pakshirajan, K. Real-time lipid production and dairy wastewater treatment using Rhodococcus opacus in a bioreactor under fed-batch, continuous and continuous cell recycling modes for potential biodiesel application. Biofuels. 2018. https://doi.org/10.1080/17597269.2017.1336347

40. Hall, J., Hetrick, M., French, T., Hernandez, R., Donaldson, J., Mondala, A., Holmes, W., \& Mississippi State University. Oil 
production by a consortium of oleaginous microorganisms grown on primary effluent wastewater. Journal of chemical technology and biotechnology. 2011. https://doi.org/10.1002/jctb.2506

41. Liu, J.-X., Yue, Q.-Y., Gao, B.-Y., Wang, Y., Li, Q., \& Zhang, P.-D. Research on microbial lipid production from potato starch wastewater as culture medium by Lipomyces starkeyi. Water science and technology. 2013. https://doi.org/10.2166/wst.2013.059

42. Yeesang, C., \& Cheirsilp, B. Low-Cost Production of Green Microalga Botryococcus braunii Biomass with High Lipid Content Through Mixotrophic and Photoautotrophic Cultivation. Applied biochemistry and biotechnology. https://doi.org/10.1007/s12010014-1041-9

43. Arun, J., Gopinath, K. P., SundarRajan, P., Felix, V., JoselynMonica, M., \& Malolan, R. A conceptual review on microalgae biorefinery through thermochemical and biological pathways: Bio-circular approach on carbon capture and wastewater treatment. Bioresource technology reports.

2020. https://doi.org/10.1016/i.biteb.2020.100477

44. Lam, M. K., Loy, A. C. M., Yusup, S., \& Lee, K. T. Chapter 9 Biohydrogen Production From Algae. Biomass, Biofuels, Biochemicals. 2019. https://doi.org/https://doi.org/10.1016/B978-0444-64203-5.00009-5

45. Altunoz, M., Allesina, G., Pedrazzi, S., \& Guidetti, E. Integration of biological waste conversion and wastewater treatment plants by microalgae cultivation. Process biochemistry. 2020. https://doi.org/10.1016/j.procbio.2019.12.007

46. Abdel-Raouf, N., Al-Homaidan, A. A., \& Ibraheem, I. B. M Microalgae and wastewater treatment. Saudi Journal of Biological Sciences. 2012. https://doi.org/10.1016/j.sjbs.2012.04.005

47. Sayre, R. Microalgae: The potential for carbon capture. BioScience. 2010. https://doi.org/10.1525/bio.2010.60.9.9

48. Cai, T., Park, S. Y., \& Li, Y. Nutrient recovery from wastewater streams by microalgae: Status and prospects. Renewable and Sustainable $\quad$ Energy $\quad$ Reviews. 2013. https://doi.org/10.1016/j.rser.2012.11.030

49. Ryu, B. G., Kim, J., Farooq, W., Han, J. I., Yang, J. W., \& Kim, W. Algal-bacterial process for the simultaneous detoxification of thiocyanate-containing wastewater and maximized lipid production under photoautotrophic/photoheterotrophic conditions. Bioresource Technology. 2014. https://doi.org/10.1016/j.biortech.2014.03.084

50. Markou, G., Chatzipavlidis, I., \& Georgakakis, D. Cultivation of Arthrospira (Spirulina) platensis in olive-oil mill wastewater treated with sodium hypochlorite. Bioresource Technology. 2012. https://doi.org/10.1016/j.biortech.2012.02.098

51. Venkata Subhash, G., \& Venkata Mohan, S. Biodiesel production from isolated oleaginous fungi Aspergillus sp. using corncob waste liquor as a substrate. Bioresource Technology. 2011. https://doi.org/10.1016/j.biortech.2011.06.084

52. Zhan, J., Zhang, Q., Qin, M., \& Hong, Y. Selection and characterization of eight freshwater green algae strains for synchronous water purification and lipid production. Frontiers of Environmental Science and Engineering. 2016. https://doi.org/10.1007/s11783-016-0831-4

53. Muniraj, I. K., Xiao, L., Hu, Z., Zhan, X., \& Shi, J. Microbial lipid production from potato processing wastewater using oleaginous filamentous fungi Aspergillus oryzae. Water Research. 2013. https://doi.org/10.1016/j.watres.2013.03.046

54. Bhanja, A., Minde, G., Magdum, S., \& Kalyanraman, V. Comparative Studies of Oleaginous Fungal Strains ( Mucor circinelloides and Trichoderma reesei ) for Effective Wastewater Treatment and Bio-Oil Production. Biotechnology Research International. 2014. https://doi.org/10.1155/2014/479370

55. Du, Y., Wang, Y., Peng, G., Su, Z., Xu, M., Feng, W., Zhang, S., Ding, Y., Zhao, D., \& Liu, P. Reducing COD and BOD, as well as producing triacylglycerol by LDS5 grown in CTMP effluent. BioResources. 2011. https://doi.org/10.15376/biores.6.3.3505-3514

56. Field, J. A., Lettinga, G., \& Geurts, M. The methanogenic toxicity and anaerobic degradability of potato starch wastewater phenolic amino acids. Biological Wastes. 1987. https://doi.org/10.1016/02697483(87)90145-5

57. Ahammad, S. Z.; Gomes, J.; Sreekrishnan, T. R. Wastewater treatment forproductionofH2S-free biogas. Journal of Chemical Technology \& Biotechnology. 2008. https://doi.org/10.1002/jctb

58. Liu, J. X., Yue, Q. Y., Gao, B. Y., Ma, Z. H., \& Zhang, P. D. Microbial treatment of the monosodium glutamate wastewater by Lipomyces starkeyi to produce microbial lipid. Bioresource Technology. 2012. https://doi.org/10.1016/j.biortech.2011.12.022

59. Chebbi, H., Leiva-Candia, D., Carmona-Cabello, M., Jaouani, A., \& Dorado, M. P. Biodiesel production from microbial oil provided by oleaginous yeasts from olive oil mill wastewater growing on industrial glycerol. Industrial Crops and Products. 2019. https://doi.org/10.1016/j.indcrop.2019.111535

60. Deeba, F., Pruthi, V., \& Negi, Y. S. Aromatic hydrocarbon biodegradation activates neutral lipid biosynthesis in oleaginous yeast. Bioresource $\quad 2018$. https://doi.org/10.1016/j.biortech.2018.01.096

61. Gen, Q., Wang, Q., \& Chi, Z. M. Direct conversion of cassava starch into single cell oil by co-cultures of the oleaginous yeast Rhodosporidium toruloides and immobilized amylases-producing yeast Saccharomycopsis fibuligera. Renewable Energy. 2014. https://doi.org/10.1016/j.renene.2013.08.016

62. Anbarasan, T., Jayanthi, S., \& Ragina, Y. Investigation on Synthesis of Biodiesel from Distillery Spent Wash using Oleaginous Yeast Metschnikowia Pulcherrima. Materials Today: Proceedings. 2018. https://doi.org/10.1016/j.matpr.2018.11.063

63. Xue, F., Gao, B., Zhu, Y., Zhang, X., Feng, W., \& Tan, T. Pilot-scale production of microbial lipid using starch wastewater as raw material. Bioresource Technology. 2010. https://doi.org/10.1016/j.biortech.2010.01.124

64. Hongyang, S., Yalei, Z., Chunmin, Z., Xuefei, Z., \& Jinpeng, L. Cultivation of Chlorella pyrenoidosa in soybean processing wastewater. Bioresource 2011. https://doi.org/10.1016/j.biortech.2011.08.016

65. Muniraj, I. K., Xiao, L., Hu, Z., Zhan, X., \& Shi, J. Microbial lipid production from potato processing wastewater using oleaginous filamentous fungi Aspergillus oryzae. Water Research. 2013. https://doi.org/10.1016/j.watres.2013.03.046

66. Zeng, Y., Xie, T., Li, P., Jian, B., Li, X., Xie, Y., \& Zhang, Y. Enhanced lipid production and nutrient utilization of food waste hydrolysate by mixed culture of oleaginous yeast Rhodosporidium toruloides and oleaginous microalgae Chlorella vulgaris. Renewable Energy. 2018. https://doi.org/10.1016/j.renene.2018.04.020

67. Chan, Y. J., Chong, M. F., Law, C. L., \& Hassell, D. G. A review on anaerobic-aerobic treatment of industrial and municipal wastewater. $\begin{array}{lll}\text { Chemical Engineering } & \text { Journal. }\end{array}$ https://doi.org/10.1016/j.cej.2009.06.041

68. Angerbauer, C., Siebenhofer, M., Mittelbach, M., \& Guebitz, G. M. Conversion of sewage sludge into lipids by Lipomyces starkeyi for biodiesel production. Bioresource Technology. 2008. https://doi.org/10.1016/j.biortech.2007.06.045

69. Pirozzi, D., Ausiello, A., Zuccaro, G., Sannino, F., \& Yousuf, A. Culture of oleaginous yeasts in dairy industry wastewaters to obtain lipids suitable for the production of II-generation Biodiesel. Proteins. 2014. http://doi.org/10.5281/zenodo.1077070

70. Goswami, L., Tejas Namboodiri, M. M., Vinoth Kumar, R., Pakshirajan, K., \& Pugazhenthi, G. Biodiesel production potential of oleaginous Rhodococcus opacus grown on biomass gasification wastewater. $\quad$ Renewable $\quad$ Energy. 2017 https://doi.org/10.1016/j.renene.2016.12.044

71. Eida, M. F., Darwesh, O. M., \& Matter, I. A. Cultivation of oleaginous microalgae Scenedesmus obliquus on secondary treated municipal wastewater as growth medium for biodiesel production. Journal of Ecological Engineering. 2018 https://doi.org/10.12911/22998993/91274

72. Cho, H. U., Cho, H. U., Park, J. M., Park, J. M., \& Kim, Y. M. Enhanced microalgal biomass and lipid production from a consortium 
of indigenous microalgae and bacteria present in municipal wastewater under gradually mixotrophic culture conditions. Bioresource Technology.

2017. https://doi.org/10.1016/j.biortech.2016.12.094

73. Chen, X. fang, Huang, C., Xiong, L., Chen, X. de, Chen, Y., \& Ma, L. long. Oil production on wastewaters after butanol fermentation by oleaginous yeast Trichosporon coremiiforme. Bioresource Technology. 2012. https://doi.org/10.1016/j.biortech.2012.05.023

74. Hall, J., Hetrick, M., French, T., Hernandez, R., Donaldson, J., Mondala, A., Holmes, W., \& Mississippi State University. Oil production by a consortium of oleaginous microorganisms grown on primary effluent wastewater. Journal of chemical technology and biotechnology. 2011. https://doi.org/10.1002/jctb.2506

75. Patel, A., Arora, N., Pruthi, V., \& Pruthi, P. A. Biological treatment of pulp and paper industry effluent by oleaginous yeast integrated with production of biodiesel as sustainable transportation fuel. Journal of Cleaner 2017. https://doi.org/10.1016/j.jclepro.2016.10.184

76. Deeba, F., Pruthi, V., \& Negi, Y. S. Bioresource Technology Converting paper mill sludge into neutral lipids by oleaginous yeast Cryptococcus vishniaccii for biodiesel production. Bioresource Technology. 2016. https://doi.org/10.1016/j.biortech.2016.02.105

77. Samir, S., Al-tohamy, R., Koutra, E., El-naggar, A. H., Kornaros, M., \& Sun, J. Valorizing lignin-like dyes and textile dyeing wastewater by a newly constructed lipid-producing and lignin modifying oleaginous yeast consortium valued for biodiesel and bioremediation. $\begin{array}{llll}\text { Journal of Hazardous } & \text { Materials. }\end{array}$ https://doi.org/10.1016/j.jhazmat.2020.123575

78. Ochoa-Herrera, V., Banihani, Q., León, G., Khatri, C., Field, J. A., \& Sierra-Alvarez, R. Toxicity of fluoride to microorganisms in biological wastewater treatment systems. Water Research. 2009. https://doi.org/10.1016/j.watres.2009.04.032

79. Ochoa-Herrera, V., León, G., Banihani, Q., Field, J. A., \& SierraAlvarez, R. Toxicity of copper(II) ions to microorganisms in biological wastewater treatment systems. Science of the Total Environment. 2011. https://doi.org/10.1016/j.scitotenv.2011.09.072

80. Praveen, P., \& Loh, K. C. Photosynthetic aeration in biological wastewater treatment using immobilized microalgae-bacteria symbiosis. Applied Microbiology and Biotechnology. 2015. https://doi.org/10.1007/s00253-015-6896-3

81. Gregory, J., \& Dhond, R. V. Wastewater treatment by ion exchange. Water Research. 1972. https://doi.org/10.1016/0043-1354(72)901832

82. El-Gohary, F., \& Tawfik, A. Decolorization and COD reduction of disperse and reactive dyes wastewater using chemical-coagulation followed by sequential batch reactor (SBR) process. Desalination. 2009. https://doi.org/10.1016/j.desal.2009.05.010

83. Cheryan, M., \& Rajagopalan, N. Membrane processing of oily streams. Wastewater treatment and waste reduction. Journal of Membrane Science. 1998. https://doi.org/10.1016/S03767388(98)00190-2

84. Huang, C., Chen, X. fang, Xiong, L., Chen, X. de, Ma, L. long, \& Chen, Y. Single cell oil production from low-cost substrates: The possibility and potential of its industrialization. Biotechnology Advances. 2013. https://doi.org/10.1016/j.biotechadv.2012.08.010

85. Mu, D., Liu, H., Lin, W., Shukla, P., \& Luo, J. Simultaneous biohydrogen production from dark fermentation of duckweed and waste utilization for microalgal lipid production. Bioresource Technology. 2020. https://doi.org/10.1016/j.biortech.2020.122879

86. Diamantopoulou, P., Stoforos, N. G., Xenopoulos, E., Sarris, D. Psarianos, D., Philippoussis, A., \& Papanikolaou, S. Lipid production by Cryptococcus curvatus growing on commercial xylose and subsequent valorization of fermentation waste-waters for the production of edible and medicinal mushrooms. Biochemical Engineering Journal. 2020 https://doi.org/10.1016/j.bej.2020.107706 